\title{
ACESSO À JURISDIÇÃO DA JUSTIÇA NOS CONFLITOS COMPLEXOS: CONTRIBUIÇÃO DA EXPERIÊNCIA ROMANA A SOLUÇÓES POR AUDIÊNCIA PÚBLICA JUDICIAL OU EXTRAJUDICIAL DELIBERATIVA
}

\author{
ACCESS TO THE JURISDICTION OF \\ JUSTICE IN COMPLEX CONFLICTS: \\ CONTRIBUTION OF THE ROMAN EXPERIENCE TO SOLUTIONS BY \\ DELIBERATE JUDICIAL OR EXTRAJUDICIAL PUBLIC HEARING
}

JOSÉ ISAAC PILATI ${ }^{1}$

ORIDES MEZZAROBA ${ }^{2}$

\section{RESUMO}

Com o método de ensino do Mestrado Profissional em Direito da UFSC, cuja área de concentração é Acesso à Justiça, o artigo aventa, com base nas fontes e na iurisdictio romanas, uma teoria para a participação popular nos conflitos complexos, através de audiência pública judicial deliberativa. Exemplifica com uma proposta de estrutura institucional e de rito processual próprio, elaborados junto a operadores jurídicos no Brasil. 0 resultado aponta para uma teoria própria, e um texto modelo para orientação prática.

PALAVRAS-CHAVE: Audiência pública. Jurisdição. Acesso à justiça. Conflito complexo. Bens coletivos.

\section{SUMMARY}

With the teaching method of the professional master in law of UFSC, whose area of concentration is access to justice, the article is based on the Roman sources and lurisdictio, with a theory for popular participation in complex conflicts, through audience Deliberative judicial public. Exemplifies with a proposal of institutional structure and own procedural rite, elaborated with legal operators in Brazil. The result points to a theory of its own, and a model text for practical guidance.

KEYWORDS: Public hearing. Jurisdiction Access to justice. Complex conflict. Collective assets.

1 Professor Titular (Graduação e Pós-graduação, Mestrado e Doutorado) da Universidade Federal de Santa Catarina. jipilati@ matrix.com.br.

2 Professor Titular e Coordenador do Mestrado Profissional em Direito da Universidade Federal de Santa Catarina. Pesquisador de Produtividade do CNPq. oridesmezza@gmail.com.

Agências de fomento: Fundação Boiteux; Tribunal de Justiça do Estado de Santa Catarina. 


\section{INTRODUÇÃO}

O Mestrado Profissional em Direito da Universidade Federal de Santa Catarina (2019) ${ }^{3}$, criado em 2015 e instalado em novembro de 2016, vem provocando grande impacto na metodologia do ensino jurídico e na introdução de novas tecnologias de acesso à Justiça (Universidade Federal de Santa Catarina, 2019) ${ }^{4}$ no Brasil: o estudante é desafiado a partir de um caso concreto da sua experiência profissional, a descrever o problema na sua casuística e a construir soluções com auxílio de aportes teóricos do Curso, da instituição em que labora e da pesquisa a que se devota.

Esse tipo de postura metodológica contrasta com o modelo tradicional do ensino jurídico brasileiro, que prefere privilegiar o caminho inverso, de partir do abstrato para o concreto. Este trabalho devota-se ao problema, e trata de comparar as experiências, romana: casuística; e moderna: metafísica e fragmentada. Duas matrizes estanques, teoricamente separadas, mas historicamente indissociáveis, que se defrontam perante os conflitos complexos dos tempos atuais; os quais apontam para a necessidade de rever todo o padrão do pensamento jurídico reinante nos últimos séculos e construir um novo modelo.

Tendo por objeto essa questão e esta proposta, sob o viés do ensino universitário do Direito, o artigo vê o raciocínio jurídico propriamente dito, como o processo mental e técnico que se realiza em contextos normativos e jurisdicionais, voltado à decidibilidade dos conflitos. Pressupõe o raciocínio jurídico, a existência de um método próprio sob um conjunto de fórmulas válidas, às quais se possa validamente recorrer. Os romanos ensinaram que o ius às vezes se aplica ao pertinente e às vezes se constrói sob a medida para o caso concreto.

Disse May (1907, p. 59 et seq) que o Direito, em sendo um fenômeno histórico, as pessoas e as coisas recebem dele uma versão artificial e técnica, em que não prepondera ponto de vista ou aspecto das suas qualidades naturais. A pessoa passa à condição de persona, papeis a desempenhar, e as coisas (res) tornam-se objeto de direitos, na situação de bens (bona); o que dá origem, nos conflitos e na perspectiva histórica, aos ritos: legis actiones.

Pelo sistema formulário (per formulas), completa Maynz (1891, p. 498), o iudicium romano foi simplificado por uma série de medidas que culminaram na Lei Ebúcia, em fins da República, mas anteriormente a Cícero. Esse é o período a que se reporta este artigo, ao falar das fontes, considerando, ainda, as duas leis Iuliae que reformaram a lei Ebúcia sob Augusto e deram completa feição ao processo formulário, conforme Gaio (CORREIA, 1955, p. 1-289).

Disse Aristóteles (2011, p. 44) na Poética (4.5) que a poesia nasce da propensão à imitação desde os primeiros conhecimentos da pessoa; e da realidade natural de que a imitação proporciona prazer. E que não é função do poeta o relato fiel dos fatos, no modo que se impõe ao historiador; porque o compromisso dele, poeta, é com o universal, não com o particular: ele expressa, no belo, a dimensão estética da sua visão de mundo. Já o Direito, cumpre acrescentar, procura imitar a si mesmo; com método próprio e compartilhado de lidar

3 A Área de Concentração é Direito e Acesso à Justiça. Linhas de pesquisa: Acesso à justiça e formas alternativas de resolução de conflitos: a administração da justiça sob o enfoque do diálogo; e acesso à Justiça e processo judiciais e administrativos: a administração da justiça sob o enfoque do combate.

4 Visando a produzir impacto nas instituições públicas a que pertencem seus discentes, o Curso promove: Seminário Acesso à justiça e novas tecnologias. Programa de Pós-Graduação profissional em Direito da Universidade Federal de Santa Catarina. Florianópolis, 10-11 jun. 2019. Disponível em http://mpd.posgrad.ufsc.br/, acesso em 10 jun. 2019. 
tecnicamente com os fatos enquanto provas, perante a existência objetiva de um conflito a decidir em dado ordenamento.

O raciocínio jurídico, em outras palavras, persegue de forma constante e perpétua a justiça, no anseio de dar a cada qual o que é seu. Mas Justiça não é vingança. Aquilo que é justo, não nasce da justa indignação, mas da equidade, já disse o Digesto 2.2.1 (PILATI, 2013, p. 40) ${ }^{5}$. Os fatos Interessam para o jurista, assim e nesse contexto, na dimensão de prova, que se submete a versão e argumento, na busca da decisão necessária.

Porém, voltando ao objetivo geral do artigo, as coisas não são tão simples, quando se coteja a justiça moderna com a iuris dictio romana, a propósito dos conflitos complexos que ameaçam o planeta, à revelia do ultrapassado modelo vigente. Eis o problema. E o que almeja, enfim, o artigo é apontar um rumo para a solução dos conflitos complexos através da autocomposição, mediante audiência pública judicial participativa e deliberativa.

Conflitos complexos, para o texto, são aqueles que envolvem interesses da coletividade em qualquer aspecto, incluindo os de grande repercussão social, demandas repetitivas e demandas provocadas por grandes litigantes. Da mesma forma aqueles que dizem respeito a direitos fundamentais coletivos, como o ambiente e o plano diretor participativo dos municípios. Porque a densidade e multiplicidade de interesses e de pessoas não abrem outra perspectiva que não a da autocomposição, a envolver autoridades de diversas esferas, além da condução de magistrado competente.

O texto é desenvolvido em cinco seções: a primeira pertinente à dimensão das fontes romanas, contextualizadas nos planos: político, filosófico, jurídico e jurisdicional. A segunda relativa à dimensão moderna do direito, com destaque ao tratamento metafísico do conflito, que ela opera. A terceira voltada à decibibilidade dos conflitos complexos, que desafiam a aproximação dos dois modelos, antigo e moderno; no rumo de uma fusão em novo paradigma, que nasce do questionamento da estrutura e da cultura jurídica reinante; esta demasiadamente voltada para a dimensão individualista e autocrática, inadequada para o enfrentamento dos conflitos complexos.

E a quinta seção é um relato de pesquisa realizada pelo autor deste artigo junto à Justiça do Trabalho da $12^{\text {a }}$ Região, em Santa Catarina, que culminou com uma proposta de estrutura e de procedimento adequados para audiência pública na Justiça do Trabalho. A conclusão, assim, é com uma proposta concreta de institucionalização da audiência pública, teoria e prática, no Brasil.

\section{A DIMENSÃO DAS FONTES: O MODELO ROMANO DE JURISDIÇÃO SOB A LEI EBÚCIA}

Um dos grandes erros no estudo das fontes é restringir-se o intérprete ao aspecto jurídico, sem se preocupar com o arcabouço: histórico, político, filosófico e jurisdicional da experiência revisitada; cumpre a ele, sem dúvida, conhecer e levar em conta a real distância

5 Literalmente: Hoc Edictum summam habet aequitatem e sine cuiusquam indignatione iusta. 
entre as duas épocas, a sua e a outra a que se reporta; enfim, e o mais importante, para uma leitura transformadora das fontes é necessário que se parta de uma teoria transformadora do presente. Sem isso não avança.

No caso deste artigo, a visita que faz às fontes baseia-se, em grande parte, na teoria pós-moderna do Direito (PILATI, 2011). Em síntese, a teoria propõe a superação da dicotomia moderna de público-privado; trazendo à baila, em contrapartida e por inspiração no direito romano, a trilogia dos bens em nova configuração: públicos, privados e coletivos. Coletivos são aqueles direitos sociais fundamentais, tal qual o ambiente, que pertencem a todos os cidadãos, em condomínio extrapatrimonial.

Na raiz da proposta está uma ideia de recuperação da soberania direta dos cidadãos, para poderem existir e atuar coletivamente no plano político e jurídico, no sistema representativo; e assim poderem deliberar em audiência pública judicial participativa em nível exercício de direito coletivo. Com isso, a função social, por seu turno, deixa de ser sinônimo de solidariedade, meramente, já que os interesses econômicos podem esbarrar em direitos autônomos, de outros titulares, tal qual se observa, mutatis mutandis, nos direitos de vizinhança.

Tal ideia é de inspiração romana, porque no plano político, o final da república é de democracia direta em Roma: a soberania reside no populus. As leis são de iniciativa da magistratura, são aprovadas pelo populus e confirmadas pela auctoritas patrum do Senado e bem assim, pelo T de concordância assinado pelo Tribuno da Plebe. Não é uma lei representativa, portanto. Também se deve notar que ainda não se empregava a palavra derectum (de inspiração judaico-cristã) e sim o termo ius para representar todo o sistema de justiça (PARICIO; BARREIRO, 2010, p. 22) ${ }^{6}$. E que a propriedade ainda era de caráter familiar e não individual, como o seria na constituição moderna.

No plano dos valores, a Roma de então era voltada ao fortalecimento das famílias com vistas no poderio militar e na subjugação dos povos, e não no desenvolvimento de um sistema econômico-financeiro aos moldes modernos de hegemonia. E a iuris dictio, sob o ordo iudiciorum privatorum constituía-se num grande sistema arbitral privado, longe do feitio estatal que mais tarde se implantaria sob a égide representativa em que hoje se vive.

O iudicium realizava-se em duas fases, pelo sistema formulário, então, vigente, e sob a batuta do Pretor; um magistrado civil temporário, eleito pelo populus, que assume baixando o seu edito, pelo qual introduz novos interditos, novas ações e exceções, para enfrentar os novos conflitos (hoje talvez se diga: novos direitos); e preside um processo que mais ordena (na fase in iure), sem preocupação em condenar. Somente se cogita de condenação na segunda fase (apud iudicem), que corria perante juiz ou árbitros de escolha das partes; e o julgamento era baseado no ius ou no fato, na boa-fé, na equidade, enfim, conforme a especificidade do conflito, habilitada na fórmula.

0 processo pertence às partes, porque em verdade se instaura entre condôminos da coisa pública, que ademais, têm a prerrogativa de escolher qualquer cidadão para exercer o papel de iudex (nas causas mais simples) ou de arbitri (quando o julgamento deveria ser por equidade e por mais de um julgador). E assim enfrentavam os romanos as transformações e 
os novos conflitos pela via da iuris dictio, e não por leis representativas estatais, nos moldes da modernidade.

Em suma e para encerrar esta parte: o processo judicial complexo e participativo de autocomposição só pode ser construído juridicamente no Brasil, se a teoria e a cultura jurídica aprenderem, com o direito romano, como se procede em jurisdição de democracia direta. Porque a modernidade, como se pode observar da próxima seção, não tem forma nem figura de modelo para comportá-lo.

\section{A DIMENSÃO MODERNA: O MODELO ESTATAL}

Para abordar o sistema atual cumpre, antes de tudo, ter presente que a modernidade está voltada, no plano dos valores, à racionalidade econômica. Tudo o que existe fora de nós, as res como definiam os romanos, ela destina precípua, politica e juridicamente ao jogo dos interesses econômicos. E nesse sentido toda a ciência caminha e se governa por tecnologias de lucro e de acumulação; de sorte que o crescimento populacional e tecnológico acirra e acelera, por exemplo, a destruição ambiental. Porque o ambiente não é propriedade no sentido forte do termo, de propriedade privada. Ao chamar o ambiente de "direito", o verdadeiro sentido, na prática, é que ambiente é um caso de polícia, à mercê do voluntarismo estatal.

A roupagem política de tal desígnio filosófico (ou econômico mais propriamente) é um traje de encomenda: o sistema representativo, de democracia indireta. Um modelo engenhoso, que alinha as políticas públicas à atividade econômica hegemônica, de livre iniciativa sob o controle estatal frouxo e às vezes conivente. 0 populus da época romana deu lugar à dicotomia: Estado (com a supremacia de direito público estatal) e Sociedade Civil (amorfa e juridicamente, inexistente, limitada a maiorias eleitorais). 0 debate eleitoral, já denunciava Nabuco (2015, p. 35), pouco avança, além das acusações e moralismos pessoais.

No plano jurídico é um sistema que opera através da estatização do coletivo, ou seja, da desclassificação automática dos interesses extrapatrimoniais coletivos, assim relegados a uma tutela de segunda classe, a cargo de um Estado leniente, tal como acontece com as reservas florestais perante a sanha incontrolável do desmatamento. Porque todo o sistema está voltado para a exploração econômica, e proteger o ambiente, investir em saúde, em educação é caro e antieconômico para o pensamento reinante.

Nesse contexto, a atividade jurisdicional torna - a cargo do Estado e seu poder autocrático - o juiz a boca da lei (representativa), ou pouco mais do que isso; já que opera um sistema voltado para conflitos individuais, previamente recortados e embalados para consumo de um ordenamento que não se compadece dos conflitos na sua complexidade real. Tende a trabalhar no plano de formalidades e questões técnicas, já que a verdade do conflito é previamente excluída da apreciação, porque o modelo em si é intocável.

O conflito ganha sob a modernidade uma dimensão metafísica, de operação abstrata por subsunção, e as próprias palavras, como disse Wilde $(2017, \text { p. } 74)^{7}$, desviam-se, sob a

7 Nesse contexto, diz Wilde, todas as formas de governo estão fadadas ao fracasso (p. 38); porque o modelo de propriedade estorva (p. 33) o desenvolvimento do (verdadeiro) Individualismo. 
tirania da autoridade política, do sentido próprio e verdadeiro, para expressar o anverso de sua exata significação. Fecha-se o espaço humano vital da intuição, como diz Nietzsche (2017, p. 52), e na mesmice os gênios ordinários têm uma grotesca habilidade para, diante do dito mais profundo e rico, nada ver a não ser sua própria opinião corrente.

\section{A DIMENSÃO DOS CONFLITOS COMPLEXOS: NECESSIDADE DE REVISÃO DO SISTEMA}

As limitações do modelo jurídico-político hodierno revelam-se em toda a extensão perante os conflitos de maior complexidade, que ele não consegue resolver, e que hoje afetam todo planeta e a própria economia; é o caso do aquecimento global e das grandes tragédias ambientais, tal qual o rompimento de barragens de rejeitos de minério em Minas Gerais, no Brasil (CASTRO, 2019). São problemas que não se resolvem no âmbito das políticas públicas e dos instrumentos estatais ordinários de polícia, estes que são muito mais voltados para serem condescendentes com a causa do que comprometidos com a solução e a prevenção.

Conflitos complexos, portanto, são os que decorrem da economia global em rede; de atividades que tendem a jogar o custo ambiental para a periferia e transferem as vantagens para os países centrais. É o agrotóxico, o desmatamento, a poluição da atividade minerária; como é o risco das barragens de contenção de rejeitos no Brasil. São conflitos que afetam indiscriminadamente pessoas, bens, patrimônios e direitos de populações inocentes, em decorrência direta do modelo jurídico que privilegia determinada atividade econômica, e relega a verdadeira segurança jurídica a uma tutela de segunda classe.

Isso acontece porque os demais direitos, que o Estado relega, estão rebaixados ab ovo pelo sistema jurídico em vigor no mundo, entregues que estão aos azares do voluntarismo estatal no plano interno e às reuniões de cúpula no plano externo; colegiados em que prevalece a vontade hegemônica daqueles que se beneficiam da distorção. E assim, por fazer tanto tempo que as coisas assim são, parece normal o Direito ser inane e aparentemente descomprometido com conflitos de maior impacto social. Perante tragédias como a de Brumadinho em Minas Gerais, parece que tudo se resume em identificar culpados e perseguir indenizações, sem tocar nas causas para a prevenção e a substituição das tecnologias oportunistas e antieconômicas.

Trata-se de um modelo que se nega a devolver aos cidadãos a condição de populus, como titular dos bens coletivos; que desde muito tempo excluiu dos ordenamentos jurídicos a fase in iure do processo romano, em que o magistrado mais ordenava e lidava com cidadãos soberanos, deixando o ato de condenar para o segundo momento, já no plano dos efeitos, depois de esgotado o espaço de criação de direito para o caso concreto.

A questão nessas condições é uma só: como restabelecer o papel do Direito para que atue em tempo real, na velocidade de hoje, como mediador de todo e qualquer conflito complexo? Como instrumento de absorção do novo, enfrentando o desafio das novas tecnologias sem negar a essência do suum cuique tribuere? Não resta dúvida que cumpre recuperar os três elementos do tríptico de Gaio: restabelecer a soberania da pessoa enquanto populus; 
superar o público e privado tradicional da Modernidade, e devolver aos cidadãos o condomínio sobre os bens coletivos, tal qual o do ambiente equilibrado e saudável; enfim, resgatar no plano das actiones o processo coletivo complexo, de participação popular deliberativa, de autocomposição.

\section{ESBOÇO DE UM MODELO PARA TRATAR DOS CONFLITOS COMPLEXOS: NOVOS PAPEIS PARA OS SUJEITOS PROCESSUAIS A PARTIR DA CRFB/88}

Não se trata de excluir o Estado, ou desautorizar sua jurisdição autocrática; e sim de otimizar o sistema na plenitude constitucional do art. $1^{\circ}$ da Constituição da República Federativa do Brasil-CRFB/88, que estabelece no parágrafo único que a soberania é exercida: por meio de representantes eleitos ou diretamente, nos termos desta Constituição.

O sistema de jurisdição complexa abarca necessariamente as duas dimensões da soberania: a representativa e autocrática, no que de ordinário lhe compete; e a participativa, de exercício direto pelo populus - a propósito dos bens coletivos; ou seja, relativamente àqueles bens de que não se pode dispor individualmente e sim coletivamente. Isso descortina um novo e ampliado arcabouço jurisdicional, com inclusão de novos papeis a serem desempenhados pelos sujeitos processuais, em face dessa nova categoria de envolvimento, que são os direitos coletivos fundamentais.

Portanto, uma das dimensões da jurisdição complexa é o devido processo legal de exercício de direitos coletivos em face de outras pretensões e interesses particulares ou públicos estatais; seu objeto são bens que pertencem a toda a coletividade, tal qual o ambiente, de que somos todos condôminos. Envolve sempre pluralidade de sujeitos e de interesses, e atua perseguindo o consenso. A via processual adequada é a da audiência pública judicial deliberativa ${ }^{8}$. Não que não se possa operar extrajudicialmente; mas o envolvimento, a dimensão social é de intensidade tal e tamanha nesses casos, que a presença de um magistrado trona-se imprescindível à condução, a contento, dos atos processuais.

A outra dimensão, paralela à jurisdição complexa é a tradicional, da faceta autocrática, punitiva, condenatória. Em cada caso, cabe às partes e ao magistrado darem o devido encaminhamento à demanda em concreto, pela via participativa ou pela autocrática no que lhe compete, conforme a sua natureza e as previsões do ordenamento. Mas as duas alternativas são completamente distintas e pautam-se por formas processuais próprias.

No México, por exemplo, recentemente foi ajuizada ação judicial em defesa do ar limpo; mas pela via tradicional autocrática (FOLHA DE SÃO PAULO, 2019); o Judiciário condenou o Estado a limitar a poluição, o que certamente é muito difícil de quantificar e de executar sem reunir todos os protagonistas: poluidores, autoridades, população em geral, técnicos, cientistas e todas as informações a serem previamente colhidas.

8 Quanto à audiência púbica judicial, trabalhos anteriores, mais detalhados, em Pilati (2017) e (2015, p. 359-389). 
Um processo dessa natureza não pode seguir outra via processual que não a via da audiência pública deliberativa; que obriga o magistrado a desencadear um fórum coletivo de estudos e de encaminhamento de decisões dialogadas, em todas as esferas competentes, identificando as causas e comprometendo a todos os setores e sujeitos envolvidos. Esse magistrado forçosamente tem que se inspirar na jurisdição romana, porque o seu papel seria de ordenar e coordenar um grande mutirão em prol do desenvolvimento sustentável, a acomodar os ônus e os bônus do processo econômico.

De fato, o papel da jurisdição nesse caso é presidir e mediar um grande esforço coletivo, a reunir saberes e informações, realizar diagnósticos, viabilizar discussões de alternativas e de novas tecnologias, com o Estado participando, recebendo ordens, disponibilizando recursos e insumos, viabilizando, enfim, um processo de efetiva e soberana participação do populus na perseguição do justo e da melhor qualidade de vida. Certamente o mundo não seria mais o mesmo, pois o direito aplicável estaria sendo construído a partir da solução por consenso dos conflitos na sua própria realidade.

\section{RELATO DE UM ESTUDO TEÓRICO-PRÁTICO DE AUDIÊNCIA PÚBLICA JUDICIAL EM SANTA CATARINA}

No início de 2014, os Magistrados e a Escola Judicial do Tribunal Regional do Trabalho da $12^{\mathrm{a}}$ Região, estimulados pela politica do Conselho Nacional de Justiça no Brasil, resolveram focar-se no problema da Audiência Pública. Superar a prática da simples consulta pública e enfrentar a questão no plano do direito material e processual, desafogar o Judiciário Trabalhista das demandas repetitivas, dos grandes litigantes e dos grandes vazios jurídicos que escarnecem da Justiça. A Audiência Pública judicial participativa deveria ser esse instrumento.

Cumpria discutir e definir estrutura institucional e processo respectivo, pautados por uma nova teoria jurídica; capaz de alcançar e mediar os conflitos coletivos, caso a caso e no plano macro, mediante a autocomposição sob a égide dos direitos sociais fundamentais. Buscar uma noção ampliada dos conceitos tradicionais de parte, de conflito, de acesso à justiça, processo. Esboçar uma teoria voltada à participação no processo do Trabalho; redefinir o papel da jurisdição; e chamar para tanto o universo de magistrados envolvidos na prática do foro, no âmbito do TRT da $12^{a}$ Região.

O ponto de partida foi adotar como método o conceito de paradigma (KUHN, 2013, p. 115; MORIN, 2011; MORIN, 2000, p. 40) ${ }^{9}$ como instrumento de comparação/transformação entre: Antiguidade, Modernidade e Pós-Modernidade. A Modernidade centrada no indivíduo e no Estado, na representação política com democracia indireta, leis parlamentares e seus vínculos complementares, e que prioriza a atividade econômica, o individualismo. E a Pós-Modernidade centrada na participação política soberana da Sociedade, na noção de sujeito coletivo, de bens coletivos, no âmbito dos direitos sociais fundamentais, enfim, nos termos 
da Constituição da República Federativa do Brasil. E a Antiguidade romana como inspiração de democracia direta e de jurisdição fulcrada no populus, como um grande sistema arbitral privado.

Após um ano de discussão com cerca de cem magistrados, a proposta do Grupo foi que a audiência pública poderia ser insitucionalizada mediante duas Resoluções (PILATI, 2017, p. 137-147) a serem baixadas pela autoridade superior: a primeira criando um Núcleo Permanente de Audiência Pública - NAP; e a outra regulamentando o procedimento. Com tal solução contemplavam-se as dificuldades e obstáculos levantados pelos Juízes, de forma a conciliar a nova estrutura com as atividades normais da Justiça do Trabalho em Primeiro e Segundo Grau.

O Ato de criação do NAP seria introduzido com uma série de Consideranda: fundamento no art. $1^{\circ}$ da CRFB; acesso à justiça como acesso à ordem justa (art. $5^{\circ}, \mathrm{XXXV}$ ); política judiciária aperfeiçoada por mecanismos consensuais de solução de litígios; visando à pacificação social e à prevenção de litígios, frente à excessiva judicialização; na linha já praticada pelos tribunais, conforme Resoluções em vigor, a optar pela criação de Núcleos controladores de recursos repetitivos, além de mecanismos de composição de conflitos de massa; a necessidade de planejamento, implementação e aperfeiçoamento de ações voltadas ao cumprimento da política judiciária de pacificação dos conflitos com reflexos coletivos; enfim, a criação do Núcleo Permanente de Audiência Pública teria como objetivo a padronização das estruturas existentes, profissionalização e concretização da impessoalidade no funcionamento dos órgãos voltados aos meios autocompositivos no âmbito coletivo.

Em oito artigos, implantava-se, mediante Resolução a ser baixada pelo Presidente no Tribunal Regional do Trabalho da $12^{a}$ Região o Núcleo Permanente de Audiências Públicas - NAP, vinculado à presidência do TRT, como órgão integrante do CONAP (Núcleo Permanente de Conciliação e Apoio às Unidades Judiciárias de Primeira Instância), responsável pela coordenação do sistema de autocomposição de questões que envolvem expressiva repercussão social, demandas repetitivas e grandes litigantes.

Isso se daria com atuação integrada de Juízes e Desembargadores, mediante a participação e cooperação de pessoas, órgãos, entidades e atores sociais, econômicos e políticos, no âmbito das relações do trabalho. O NAP, especificamente, seria composto de Desembargadores (Presidente, Corregedor, Diretor da Escola Judicial) e três magistrados eleitos (um juiz substituto, um juiz titular e um desembargador). A coordenação seria do Diretor da Escola, que se conduziria conforme regras previstas nos parágrafos do art. $2^{\circ}$.

Quem indicaria os magistrados para realizar a audiência pública seria o NAP, suspendendo-se os prazos para atos decisórios de quem fosse convocado. A Escola encarregar-se-ia de promover cursos de capacitação para condução de audiência pública e os casos omissos seriam resolvidos pelo próprio NAP. Observa-se que a estrutura de coordenação das audiências públicas é um órgão à parte das atividades jurisdicionais rotineiras, e está centrada na Escola Judicial.

A segunda Resolução regulamentaria a realização das audiências públicas no âmbito do TRT, à vista da criação do NAP, com fundamento constitucional nos art. $1^{\circ}$ e $58, \S^{\circ}$ e considerando a existência de questões de superior relevância social e cujo interesse extrapola 
o das partes e reclama conhecimentos técnicos interdisciplinares e participação da Sociedade. São dezessete artigos.

0 art. $2^{\circ}$ definindo Audiência pública: para os fins desta Resolução, é instrumento de deliberação participativa e presencial conduzida por Magistrado(s) do Trabalho, com o objetivo de obter a autocomposição de conflito de expressiva repercussão social - aí incluídos os casos de demandas repetitivas e de grandes litigantes - sob a coordenação do Núcleo Permanente de Audiência Pública - NAP instituído pelo TRT da $12^{a}$ Região.

A diretriz geral (art. $3^{\circ}$ ) é a busca da autocomposição pelo consenso, reconhecendo para tanto as condições de autonomia e independência dos cidadãos como Sociedade e como indivíduos; das autoridades e agentes públicos como representantes do poder do Estado; e dos magistrados do trabalho em suas prerrogativas da jurisdição.

Podem ser considerados sujeitos e participantes, a critério da Comissão de Audiência Pública (art. $4^{\circ}$ ):

I as pessoas físicas, jurídicas e grupos de interesse em geral, sem exceção;

II as autoridades, órgãos e agentes do Estado no que tange às respectivas esferas de poder público, na forma da lei;

III os magistrados do trabalho, ainda que não integrantes da Comissão da Audiência Pública; e

IV outros órgãos, entidades e atores sociais, econômicos, políticos, acadêmicos e científicos.

As audiências públicas são convocadas e realizadas no âmbito institucional e logístico do Núcleo Permanente de Audiências Públicas- NAP, nos termos do Edital de Convocação (art. $6^{\circ}$ ). Mas qualquer magistrado ou interessado poderá propor a instauração de audiência pública sobre tema relacionado à jurisdição trabalhista; e o NAP apreciará o pedido, designará os membros da Comissão, e o magistrado coordenador.

Por solicitação ou por iniciativa própria, o NAP pode realizar outros atos de participação, como consulta pública, produção coletiva de prova para processos da mesma natureza, na forma e nos termos definidos no ato de convocação respectivo. E o magistrado ou interessado que propuser a instauração de audiência pública indicará o teor e a abrangência do conflito, com os elementos de que dispuser, assim como pode manifestar interesse em participar da Comissão responsável, sugerindo membros e participantes da audiência pública.

O NAP, conjuntamente com a Comissão designada, cuida das medidas preparatórias, providencia informações, recursos e infraestrutura necessários, e esboça a condução dos trabalhos, as formas de participação e o rol de participantes e convidados (art. $7^{\circ}$ ). Alguns protagonistas são comunicados diretamente da realização da audiência Pública (art. $8^{\circ}$ ): Procurador-Chefe do Ministério Público do Trabalho da $12^{\mathrm{a}}$ Região; Presidente da Ordem dos Advogados do Brasil - Seccional de Santa Catarina; Representante de cada entidade interessada; Diretor do Escritório da Organização Internacional do Trabalho no Brasil; e o Superintendente Regional do Trabalho e Emprego em Santa Catarina. E o art. $9^{\circ}$ permite aos Magistrados do Trabalho de Santa Catarina manifestar-se na audiência pública, em qualquer fase do processo, por qualquer meio. 
Um dos documentos mais importantes do processo é previsto no art. 10: realizadas as providências preliminares, o NAP publicará o Edital de Convocação da Audiência Pública. 0 Edital indicará (art. 11):

$$
\begin{aligned}
& \text { I - os membros da Comissão da Audiência Pública; } \\
& \text { II - o objeto; } \\
& \text { III - o objetivo; } \\
& \text { IV - a data, horário e o local da abertura da Audiência Pública; } \\
& \text { V - o rito e as formas de participação; } \\
& \text { VI - a proposta de cronograma dos atos processuais; } \\
& \text { VII - os respectivos efeitos jurídicos do processo; } \\
& \text { VIII - a relação de participantes e convidados. }
\end{aligned}
$$

A Comissão decide sobre a inclusão de novos participantes e convidados, após a publicação do edital, que será amplamente divulgado e encaminhado a todos os juízes e desembargadores do TRT da $12^{\mathrm{a}}$ Região. Cabe ao magistrado ou órgão competente, a partir da publicação do Edital, decidir acerca da suspensão dos processos que tenham relação com o objeto da audiência pública.

Os convidados devem confirmar a presença, podendo comparecer pessoalmente à audiência pública ou por meio de representante com poder de deliberar; mas o serviço de apoio, entre a publicação do Edital e a instalação da audiência pública, fará contato com os participantes a que se refere o art. $8^{\circ}$, reforçando o convite, e comunicando à autoridade judicial condutora qualquer informação relevante.

0 art. 12 dispõe sobre a sessão de instalação da audiência pública, na qual a autoridade judicial condutora:

$$
\begin{aligned}
& \text { I - advertirá os presentes sobre a natureza do processo; } \\
& \text { II - definirá os ajustes a serem feitos na proposta e no rito; } \\
& \text { III - identificará as providências complementares a serem tomadas, tais } \\
& \text { como esclarecimentos técnicos, requisições e comunicações; } \\
& \text { IV - fixará o cronograma de atividades. }
\end{aligned}
$$

Antes de qualquer deliberação, a autoridade judicial esclarece os participantes a respeito da natureza do processo que se inicia; seu caráter aberto, inclusivo e construtivo, e concitará a que exponham com clareza e sinceridade os seus interesses e as suas propostas, visando a construir em consenso a decisão mais adequada para indivíduos, Estado e Sociedade. E ao constatar ausência de participante da categoria a que se refere o artigo $8^{\circ}$, tomará as medidas necessárias para o comparecimento, na forma da lei.

$\mathrm{O}$ acesso à audiência pública é franqueado a todos aqueles que desejarem, seja no espaço físico de sua realização, seja por outros meios disponíveis, como internet, videoconferência, televisão ou rádio, conforme o caso e a decisão da autoridade judicial condutora (art. 13). 0 acesso ao espaço físico poderá ser feito mediante inscrição prévia no prazo do Edital, se assim o entender a autoridade judicial condutora. 
A participação nas deliberações será oral ou por escrito, tendo prioridade os sujeitos diretamente convocados (art. 14). E a Comissão estabelecerá, em cada caso, as condições, prazo, tempo, ordem e prioridade das manifestações, garantida a participação às diversas correntes de opinião. Todas as manifestações serão registradas e integrarão o processo da audiência pública.

O art. 15 dispõe, que concluída a audiência pública, a Comissão de Audiência Pública elaborará o Relatório Final contendo a síntese dos atos realizados, debates, propostas, provas e os resultados alcançados, sem prejuízo de outros elementos considerados relevantes. Os participantes diretamente convocados poderão firmar documento próprio, a ser homologado pela autoridade judicial condutora.

Finalmente, art. 16, o NAP encaminhará cópia do Relatório Final a todos os Magistrados do TRT da $12^{\mathrm{a}}$ Região, bem como a todos os participantes e convidados, e a disponibilizará no sítio eletrônico do TRT da $12^{\mathrm{a}}$ Região. No caso de impasse (art. 17) acerca de questão sobre andamento da audiência pública, a decisão será proferida de imediato pela autoridade judicial condutora, em caráter irrecorrível.

Como se pode observar, é um documento discutido e minucioso, que dá bem a ideia da complexidade que é um trabalho de realização de audiência pública, na linha teórica e prática defendida neste artigo. Ele pressupõe espírito público e lealdade entre os participantes.

\section{CONCLUSÃO}

Não resta a menor dúvida de que a preocupação do Mestrado Profissional em Direito da UFSC em adotar o método de partir do fato, do problema a resolver, está sintonizado com o sistema casuístico romano. E que as fontes clássicas são referência e oportuna lição para auxiliar a resolver os problemas complexos que a modernidade não consegue enfrentar, adequadamente, com seu método de partir do abstrato para o concreto. Ademais, a Antiguidade romana laborava num sistema de democracia direta, com a jurisdição fulcrada no populus e não num Estado separado e diferente dele. E assim oferece lastro para que superem os problemas da modernidade dos códigos, estruturalmente despreparada em relação à participação de que se necessita no caso de audiência pública judicial deliberativa.

As limitações do sistema jurisdicional brasileiro são evidentes perante tragédias como a de Mariana, do Rio Doce e de Brumadinho em Minas Gerais, assim como a poluição dos rios e outros tipos de problemas que o modelo jurídico não abarca e não soluciona, já que se trata de conflitos complexos; também o caso das demandas repetitivas, grandes litigantes e grande repercussão social, que sobrecarregam a justiça com uma carga impossível de absorver. Justamente quando os tempos são de velocidade e de acirramento nas necessidades de acesso justo à Justiça.

É nesse contexto de crise, que o artigo traz e trava uma discussão de cunho teórico-prático, com vista na solução da crise pela participação; propondo enfrentar esses problemas através da jurisdição complexa, à semelhança do processo romano, que se amoldava à 
natureza mesma do conflito; ou seja, acostando ao sistema de acesso à justiça a audiência pública participativa e deliberativa, sem prejuízo da jurisdição tradicional.

E assim amparado numa teoria que redefine o modelo brasileiro com nova classificação dos elementos: pessoas, bens e ações, o artigo lança mão de uma pesquisa concretamente realizada em Santa Catarina com operadores jurídicos, magistrados da Justiça do Trabalho, a qual oferece um modelo para realização de audiência pública judicial participativa e deliberativa. Duas resoluções que estabelecem, respectivamente, o arcabouço institucional e o caminho processual a seguir, no caso.

E assim se pode restabelecer, com a noção de populus soberano quanto aos bens coletivos, e afirmação da jurisdição complexa: ao lado do processo tradicional e autocrático, punitivo e condenatório, o processo participativo, de construção de consenso em torno do exercício de direitos fundamentais coletivos e extrapatrimoniais reconhecidos e garantidos pela Constituição da República Federativa do Brasil.

\section{REFERÊNCIAS}

ARISTÓTELES. Poética. Tradução de Edson Bini. São Paulo: Edipro, 2011.

CASTRO, Claudio Henrique de. A justiça e as tragédias no Brasil. http://paranaextra.com.br/a-justica-e-as-tragedias-no-brasil/, acesso 27 abr. 2019 e https://g1.globo.com/mg/minas-gerais/noticia/2019/04/24/brumadinho-chega-a-233-numero-de-mortos-identificados-em-rompimento-de-barragem-da-vale.ghtml.

FOLHA DE SÃO PAULO. Mexicanos entram na justiça por direito a ar limpo e vencem. Disponível em https://www1. folha.uol.com.br/mundo/2019/06/mexicanos-entram-na-justica-por-direito-a-ar-limpo-e-vencem.shtml?utm _ source=newsletter\&utm_medium=email\&utm_campaign=newsfolha. Acesso em 09 jun. 2019.

GAIO. Instituições. In: CORREIA, Alexandre; SCIASCIA, Gaetano; CORREIA, Alexandre Augusto de Castro. Manual de direito romano. 2 ed. São Paulo: Saraiva, 1955, v. 2-2, p. 1-289.

KUHN, Thomas s. A estrutura das revoluções científicas. Tradução de Beatriz Vianna Boeira e Nelson Boeira. 12 ed. São Paulo: Perspectiva, 2013.

MAY, Gastón. Éléments de droit romain a l'usage des étudiants des facultés de droit. Neuviène éd. Paris: Sirey, 1907.

MAYNZ, Charles. Cours de droit romain. 5ed, Bruxelles: Bruylant-Christophe, 1891, t.1.

MORIN, Edgar. O método 4: as ideias, habitat, vida, costumes, organização. Tradução de Juremir Machado da Silva. 5 ed. Porto Alegre: Sulina, 2011.

MORIN, E. A epistemologia da complexidade. In: MORIN, E; LE MONATAGNE, J. A inteligência da complexidade. Tradução de Nurimar Maria Falci. São Paulo: Peirópolis, 2000.

NABUCO, Joaquim. Minha formação. Rio de Janeiro: Saraiva, 2015.

NIETZSCHE, Friedrich Wilhelm. A filosofia na era trágica dos gregos. Tradução de Gabriel Valladão Silva. Porto Alegre: L\&PM, 2017, p. 72.

PARICIO, Javier; BARREIRO, A. Fernández. Historia del derecho romano y su recepción europea. Madrid: M. Pons, 2010.

PILATI, José Isaac. Audiência pública na justiça do trabalho. 2 ed. Rio de Janeiro: Lumen Juris, 2017. 
PILATI, José Isaac. Audiência pública na justiça do trabalho: uma proposta teórico-prática de inspiração romanista junto aos magistrados do Tribunal Regional do Trabalho da 12a Região no Brasil. Revista do Tribunal Regional do Trabalho da $12^{\text {a }}$ Região. v. 18, n. 27, 2014-2015, p. 359-389.

PILATI, José Isaac. Digesto de Justiniano: livro segundo jurisdição. Florianópolis: Edufsc, 2013

UNIVERSIDADE FEDERAL DE SANTA CATARINA. Seminário Acesso à justiça e novas tecnologias. Programa de Pós-Graduação profissional em Direito da UFSC. Florianópolis, 10-11 jun. 2019. Disponível em: http://mpd.posgrad.ufsc.br/, acesso em 10 jun. 2019.

WILDE, Oscar. A alma do homem sob o socialismo. Tradução de Heitor Ferreira da Costa. Porto alegre: L\&PM, 2017, p. 74.

Recebido/Received: 28.04.2020.

Aprovado/Approved: 19.05.2020. 